\title{
Conservative management versus endovascular or open surgery in the spectrum of type B aortic dissection
}

\author{
Xun Yuan ${ }^{1}$, Andreas Mitsis ${ }^{1}$, Mohammed Ghonem ${ }^{1}$, Ilias Iakovakis ${ }^{2}$, Christoph A. Nienaber ${ }^{1}$ \\ ${ }^{1}$ Cardiology and Aortic Centre, ${ }^{2}$ Cardiac Surgery Department, Royal Brompton \& Harefield NHS Foundation Trust and Imperial College, \\ London, UK \\ Contributions: (I) Conception and design: CA Nienaber, X Yuan; (II) Administrative support: CA Nienaber; (III) Provision of study materials or \\ patients: All authors; (IV) Collection and assembly of data: X Yuan, A Mitsis, M Ghonem; (V) Data analysis and interpretation: All authors; (VI) \\ Manuscript writing: All authors; (VII) Final approval of manuscript: All authors. \\ Correspondence to: Christoph A. Nienaber. Cardiology and Aortic Centre, Royal Brompton \& Harefield NHS Trust and Imperial College, Sydney \\ Street, London, SW3 6NP, UK. Email: C.Nienaber@rbht.nhs.uk.
}

Background: Type B aortic dissection is a life-threatening acute aortic condition often with acute ischemic signs or symptoms. With initial management focusing on alleviating malperfusion and pain, and avoiding propagation of dissection or rupture both systolic blood and pulse pressure should be reduced initially by an aggressive medical approach. In the setting of persistent signs of complications endovascular strategies have replaced open surgery and led to a fourfold increase in early survival and better long-term outcomes.

Methods: An electronic health database search was performed on articles published between January 2006 and July 2017. Publications were included in this review if (I) the index aortic pathology was type B aortic (distal) dissection; (II) when medical management, open surgical replacement or thoracic endovascular aortic repair were among those options; (III) when at least one of all basic outcome criteria such as survival, spinal cord ischemia and cerebrovascular accident was reported; (IV) when $\geq 15$ serial patients were included. A total of 62 studies were eligible and analysed.

Results: Our manuscript has summarized data collected over 12 years on management specific outcomes in the setting of distal aortic dissection and provides an up-to-date interpretation of the published evidence. For complicated cases, treated acutely, the 30-day or in-hospital mortality was $7.3 \%$ when managed by endovascular means, whereas the pooled rate for 30-day or in-hospital mortality was $19.0 \%$ when subjected to open repair. For acute uncomplicated type B dissection usually treated with blood pressure lowering medications, the pooled 30-day or in-hospital mortality rate was $2.4 \%$. Survival rates at 5 years averaged at $60 \%$ (40\% mortality). Freedom from any aortic event ranged from $34.0 \%$ to $83.9 \%$, underlining an inherent risk of progression and late complications. For chronic complicated type B dissection, the rates of stroke, paraplegia and operative mortality following endovascular repair ranged from $5 \%$ to $13 \%, 2 \%$ to $13 \%$ and 2 to $13 \%$, respectively, while 5 -year survival rates after open repair ranged from $60 \%$ to $90 \%$. In chronic uncomplicated type B dissection almost $90 \%$ of patients survive initial hospitalization and were subjected to medical management with a 5 -year survival of 50-80\%. However, up to $20-55 \%$ of medically treated patients develop aneurysmal degeneration after 5 years with an unknown risk of rupture.

Conclusions: Currently, the less invasive strategy of endovascular repair (as compared to open surgery) provides improved 30-day or in-hospital survival in the setting of complicated acute type B aortic dissection and may seek broad application. Open surgical aortic reconstruction should be left to experienced aortic centres if endovascular management is not an option.

Keywords: Distal aortic dissection; endovascular treatment; open surgery; medical therapy; literature review

Received: 28 November 2017; Accepted: 09 February 2018; Published: 23 March 2018.

doi: 10.21037 /jovs.2018.02.15

View this article at: http://dx.doi.org/10.21037/jovs.2018.02.15 


\section{Introduction}

Distal aortic dissection is a potentially life-threatening condition. Stanford type B or DeBakey IIIa/b aortic dissection classifies distal dissection originating in the descending thoracic aorta without retrograde progression into the ascending aorta (1). About a quarter of patients presenting with acute type $\mathrm{B}$ aortic dissection (aTBAD) are considered complicated upon admission with malperfusion syndromes, impending rupture or hemodynamic instability, carrying a substantial risk of early mortality if left untreated (1-3). Malperfusion syndrome may involve ischemia to viscera, kidneys or extremities and is often associated with impending rupture, uncontrolled hypertension, persistent chest/back or abdominal pain, or signs of rapid expansion on repeated scans.

Uncomplicated dissection -without those before mentioned features- has traditionally been managed medically with efficient blood pressure control. Nevertheless, medical treatment is associated with a well-known risk of expansion of distal dissected segments, which occurs as a late complication in about $30-40 \%$ of patients $(4,5)$. Preemptive management of so-called uncomplicated TBAD has recently been shown to prevent aneurysmal degeneration and impact positively on survival with a lower incidence of late complications by the induction of remodelling $(5,6)$.

We undertook a systematic review of the literature in the public domain in view of medical, surgical and endovascular treatments of aTBAD; then, eligible studies were collapsed into a meta-analysis in the intention to study the efficacy of varies treatment strategies.

\section{Methods}

\section{Search strategy}

An electronic health database search was performed on articles published from January 2006 up to July 2017 with focus on management of TBAD. The search process used the medical subject heading (MeSH) terms: "type B aortic dissection", "acute", "chronic", "complicated", "uncomplicated", "medical treatment", "surgical treatment", "open repair" and "endovascular treatment". Publications were retrieved via electronic search engines (Embase, Google Scholar, Scopus, Medline, Ovid, and the Cochrane Library). All studies were independently checked, and retrieved the full text of potentially eligible studies manually. Moreover, listed references of retrieved articles were examined for additional relevant series.

\section{Statistical analysis}

Publications were included in this review if (I) the index aortic pathology was type B aortic (distal) dissection; (II) when medical management, open surgical replacement or thoracic endovascular aortic repair (TEVAR) were among those options; (III) when at least one of all basic outcome criteria such as survival, spinal cord ischemia (SCI) and cerebrovascular accident (CVA) was reported; (IV) when $\geq 15$ serial patients were included. Publications were only accepted when written in English. Case reports and case series with less than 15 patients were not accepted. Studies referring to type A aortic dissection or to hybrid endovascular and open repair of the thoracic aorta were also not included. When repeat or overlapping publications on the identical population were identified only the latest report was included, unless reported outcomes were mutually exclusive. Several studies contained patients with both acute or chronic type B dissection; these were included only if separate outcomes data of each subgroup were reported. All data were extracted independently and analysed by four reviewers (I Iakovakis, M Ghonem, A Mitsis, X Yuan), and a consensus was reached in case of discrepancies. Peri-procedural (30-day/in-hospital) mortality, stroke, SCI and overall long-term survival were all considered primary endpoints.

\section{Results}

\section{Acute complicated TBAD}

In the acute setting of dissection, features such as rupture, malperfusion, refractory hypertension, expansion of diameter on imaging within 2 weeks of admission, persistent pain or hypertension identify complicated dissection, and prompted prompting early intervention either as TEVAR or as open surgery. Various management strategies are summarised in separate tables (Table 1). Recent studies of medication only in acute complicated type B dissection showed an excess mortality and the need for active management in this subset of patients (8).

\section{Open surgery}

Open repair was performed as a gold standard before the introduction of TEVAR; with the advent of TEVAR open repair is only reserved for patients with complicated aTBAD not amenable for TEVAR or for patients with high suspicion for connective tissue disorders such as Marfan and/or Loeys-Dietz syndrome. Adjunctive measures to open surgery such as cerebrospinal fluid drainage and distal aortic 
Table 1 Recent studies of medication only in acute complicated type B dissection

\begin{tabular}{|c|c|c|c|c|c|c|}
\hline Study & $\mathrm{n}$ & \multicolumn{3}{|c|}{ Early events } & F/U duration (months) & Survival (\%) \\
\hline \multirow[t]{2}{*}{ Chemelli-Steingruber et al., 2010 (7) } & 50 & NA & NA & NA & 12 & 92 \\
\hline & & & & & 60 & 71 \\
\hline
\end{tabular}

CVA, cerebrovascular accident; SCl, spinal cord ischemia; F/U, follow-up; NA, not available.

Table 2 Recent studies of open surgery in acute complicated type B dissection

\begin{tabular}{|c|c|c|c|c|c|c|}
\hline Study & $\mathrm{n}$ & \multicolumn{3}{|c|}{ Early events $(n)$} & F/U duration (months) & Survival (\%) \\
\hline Estrera et al., 2007 (9) & 21 & 4 & NA & NA & 20 & NA \\
\hline Trimarchi et al., 2006 (10) & 82 & 24 & 8 & 4 & NA & NA \\
\hline Bozinovski et al., 2008 (11) & 76 & 17 & 5 & 5 & NA & NA \\
\hline Zeeshan et al., 2010 (13) & 20 & 8 & 0 & 2 & 37 & NA \\
\hline Brunt et al., 2011 (14) & 991 & 173 & 61 & 25 & NA & NA \\
\hline Murashita et al., 2012 (15) & 34 & 6 & 2 & 2 & 60 & 60 \\
\hline Minami et al., 2013 (16) & 14 & 2 & 4 & NA & 12 & 86 \\
\hline
\end{tabular}

CVA, cerebrovascular accident; $\mathrm{SCl}$, spinal cord ischemia; F/U, follow-up; NA, not available.

perfusion using left heart bypass, are usually applied in all patients in a haemodynamically stable scenario. A full or modified thoracoabdominal incision is performed most of the times and the extent of the aortic replacement depends on the length of the involved aortic segment. Focusing on open surgical repair, a total of 1,276 patients from nine studies describing surgical repair for acute complicated TBAD were analysed. The pooled rate 30-day/in-hospital mortality was $19.0 \%$, while that of cerebrovascular events was $6.8 \%$, for SCI $3.3 \%$ and for all neurologic complications $9.8 \%$, respectively (Table 2). Survival ranged from $74.1 \%$ to $86.0 \%$ at 1 year and from $44.0 \%$ to $82.6 \%$ at 5 years, whereas freedom from acute aortic events could not be estimated due to missing data.

\section{Endovascular repair}

Besides a clear trend and shift towards endovascular technique in recent years, the better results on outcomes identify TEVAR as treatment modality of choice in the settings of acute complicated TBAD (Table 3). The term complicated applies to persistent or recurrent pain, uncontrolled hypertension, early aortic expansion, malperfusion or signs of rupture. Additional factors as the diameter of the false lumen $(>22 \mathrm{~mm})$, the location of the primary entry site on the inner side of the distal aorta, or retrograde dissection into the arch have recently been added to the list of bad prognostic factors (28).

Endovascular repair of the thoracic aorta (TEVAR) has changed the management algorithm for patients with acute complicated Stanford TBAD without any traumatic surgery and risks of those invasive measures (29), and is now the standard. Planning for TEVAR implies careful and precise tomographic imaging (best by CT) to identify the entry tear; it is important to identify the extension of the dissection and any possible involvement of side branches resulting in malperfusion. Most endovascular procedures are performed via femoral artery access with a stiff guide wire in the true lumen and retrograde trans-aortic advancement of a large bore device (20 to $26 \mathrm{~F}$ ) and a collapsed selfexpandable stent-graft in it. Stent-grafts are delivered over any stiff guide wire in the true lumen confirmed by transoesophageal or intravascular ultrasound. When the 
Table 3 Recent studies of endovascular repair in acute complicated type B dissection

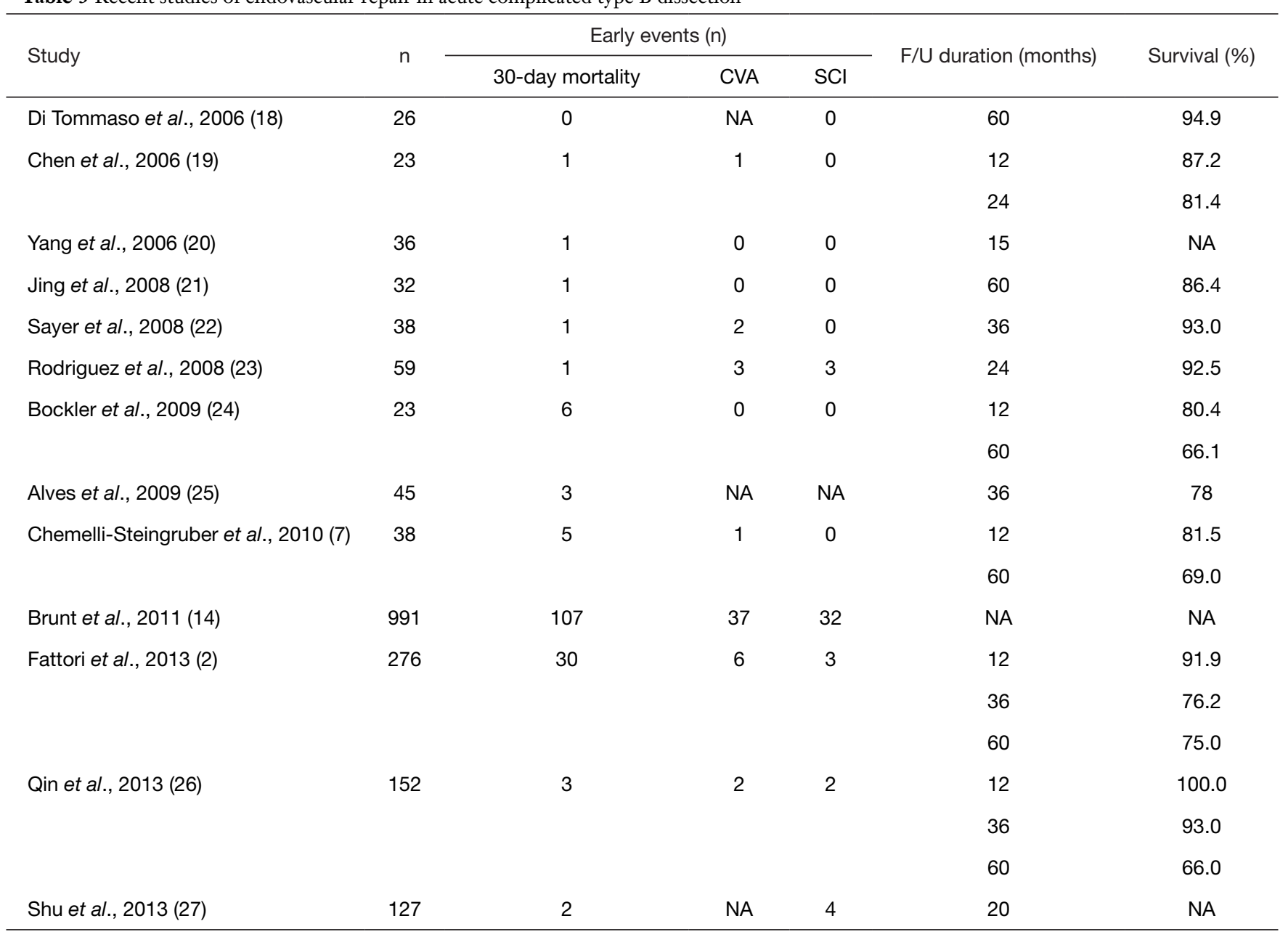

CVA, cerebrovascular accident; SCI, spinal cord ischemia; F/U, follow-up; NA, not available.

target position is reached it may be crucial to temporarily reduce blood pressure (either pharmacologically or by rapid pacing) to avoid displacement of the device. To prevent an iatrogenic (treatment-related) retrograde Stanford type A dissection endografts should be sized to the diameter of non-dissected proximal aorta, serving a landing zone in the healthy segment of the aorta (usually just proximal to the left subclavian artery) to avoid traumatic oversizing or type I endoleak; there is recent consensus that balloon dilatation should be avoided, while the length of aorta to be covered by endograft is still controversial. In the setting of a contained rupture in aortic dissection, the descending thoracic aorta should be stented from the left subclavian artery to just above the coeliac trunk to minimize retrograde perfusion of the false lumen $(30,31)$. In patients with dynamic (intermittent) malperfusion, coverage of the proximal entry tear using an endograft will usually expand the true lumen sufficiently to re-perfuse ischaemic viscera and legs. If sufficient reperfusion has not taken place, the true lumen may be expanded further distally by implantation of a bare stent (PETTICOAT technique) (32).

\section{Acute uncomplicated TBAD}

The treatment of uncomplicated aTBAD continues to be a matter of debate as pre-emptive endovascular therapy is not used to manage clinical complications, but rather to induce aortic remodelling and foster long-term stability by preventing aneurysmal degeneration and rupture.

\section{Medical management}

Uncomplicated dissections have traditionally been 
Table 4 Recent studies of medication only in acute uncomplicated type B dissection

\begin{tabular}{|c|c|c|c|c|c|c|}
\hline \multirow{2}{*}{ Study } & \multirow{2}{*}{$\mathrm{n}$} & \multicolumn{3}{|c|}{ Early events (n) } & \multirow{2}{*}{ F/U duration (months) } & \multirow{2}{*}{ Survival (\%) } \\
\hline & & 30-day mortality & CVA & $\mathrm{SCl}$ & & \\
\hline Estrera et al., 2007 (34) & 136 & 10 & NA & NA & 60 & 75.0 \\
\hline Kitada et al., 2008 (35) & 74 & 0 & NA & NA & 12 & 97.0 \\
\hline \multirow[t]{3}{*}{ Niino et al., 2009 (36) } & 210 & 6 & NA & 1 & 12 & 97.0 \\
\hline & & & & & 60 & 89.4 \\
\hline & & & & & 120 & 71.8 \\
\hline \multirow[t]{2}{*}{ Chemelli-Steingruber et al., 2010 (7) } & 50 & 3 & 1 & ND & 12 & 88.0 \\
\hline & & & & & 60 & 70.2 \\
\hline Dick et al., 2010 (37) & 72 & 4 & NA & NA & 60 & 79.0 \\
\hline \multirow[t]{2}{*}{ Miyahara et al., 2011 (38) } & 160 & 0 & NA & NA & 12 & 98.7 \\
\hline & & & & & 60 & 97.2 \\
\hline \multirow[t]{2}{*}{ Qin et al., 2013 (26) } & 41 & 0 & 0 & 0 & 12 & 100.0 \\
\hline & & & & & 60 & 59.0 \\
\hline Brunkwall et al., 2014 (33) & 31 & 0 & 0 & 0 & 12 & NA \\
\hline \multirow[t]{3}{*}{ Afifi et al., 2015 (39) } & 286 & 6 & 0 & 0 & 12 & 87.0 \\
\hline & & & & & 60 & 65.0 \\
\hline & & & & & 120 & 45.0 \\
\hline \multirow[t]{3}{*}{ Qin et al., 2016 (6) } & 154 & 4 & 0 & NA & 12 & 92.0 \\
\hline & & & & & 60 & 85.0 \\
\hline & & & & & 120 & 35.0 \\
\hline \multirow[t]{2}{*}{ Song et al., 2016 (40) } & 117 & 0 & NA & 0 & 12 & NA \\
\hline & & & & & 60 & 58.4 \\
\hline
\end{tabular}

CVA, cerebrovascular accident; SCI, spinal cord ischemia; F/U, follow-up; NA, not available.

managed medically with aggressive blood pressure lowering. However, medical management is associated with a considerable risk of disease progression to late complications and aneurysmal degeneration involving about $30-40 \%$ of patients $(6,33)$ (Table 4$)$.

\section{Endovascular repair}

The ADSORB trial as the only randomized study has compared medical treatment alone to medical treatment with TEVAR for uncomplicated TBAD (Table 5). The primary endpoint of this small trial was a cluster endpoint of incomplete/no false lumen thrombosis, aortic dilatation, or aortic rupture at 1-year follow-up. No mortality was observed within 30 days in either group; in addition, there was no difference in the overall endpoint. However, incomplete false lumen thrombosis was identified in $43 \%$ of the medical treatment with TEVAR group and in $97 \%$ of the medical treatment alone group $(\mathrm{P}<0.001)$. A reduction of false lumen diameter was only seen a stentgraft $(\mathrm{P}<0.001)$ with the true lumen expanding $(\mathrm{P}<0.001)$. The authors concluded that medical management with TEVAR in uncomplicated aTBAD leads to remodelling following thrombosis of the false lumen and reduction of its diameter (33). A poor long-term outcome in patients with uncomplicated acute type A dissection on drugs alone is well documented with $46 \%$ of patients requiring either open or endovascular intervention at a mean of 2.7 years after initial diagnosis. TEVAR could represent a low risk adjunct therapy to blood pressure lowering medication in view of remodelling and stability induced by stent-graft (6). 
Table 5 Recent studies of endovascular repair in acute uncomplicated type B dissection

\begin{tabular}{|c|c|c|c|c|c|c|}
\hline Study & $\mathrm{n}$ & \multicolumn{3}{|c|}{ Early events (n) } & F/U duration (months) & Survival (\%) \\
\hline \multirow[t]{2}{*}{ Qin et al., 2016 (6) } & 184 & 1 & 1 & NA & 12 & 94.0 \\
\hline & & & & & 60 & 90.0 \\
\hline
\end{tabular}

CVA, cerebrovascular accident; SCI, spinal cord ischemia; F/U, follow-up; NA, not available.

Conversely, according to a recent review, medical management may remain the first line of treatment in the setting of uncomplicated acute TBAD, with longterm survival of $50 \%$ to $70 \%$ (Table 4), but with the need for late interventions in $15.3 \%$ (39). There seems to be agreement that medical management plus surveillance imaging is sufficient in the short-term of the uncomplicated aTBAD. However, long-term outcomes are sobering due to a high rate of aneurysmal degeneration of the aorta and subsequent late aorta-related complications. False lumen perfusion is considered heralding adverse outcomes and late complications. With false lumen perfusion as an adverse predictor pre-emptive TEVAR could be supportive to promote false lumen thrombosis and a better long-term prognosis. Moreover, data from IRAD also suggest that TEVAR is associated with lower mortality over 5 -year period than medical management for aTBAD, corroborating a recent large multi-institutional retrospective study from China proving both feasibility of TEVAR in uncomplicated aTBAD compared with medical management and equivalent short-term mortality, and a reduction of adverse aorticrelated events and lower 5-year mortality with the use of TEVAR (6). On aggregate, it seems justified to consider pre-emptive TEVAR in the subacute period in anatomically suitable patients with a life expectancy of $\geq 2$ years.

\section{Chronic complicated TBAD}

\section{Medical management}

Patients with chronic TBAD (cTBAD) are traditionally kept blood pressure lowering medication to control blood pressure until complications develop. There is no specific antihypertensive drug, but $\beta$-blockers are often used in concert with surveillance to identify signs of disease progression or late complications; once the aortic diameter exceeds 55 to $60 \mathrm{~mm}$, the risk of rupture is estimated at
$30 \%$ per annum (41) then prompting swift surgery or endovascular complex procedures. Chronic complicated aortic dissection includes patients with early expansion $(>55 \mathrm{~cm})$ or an increase in diameter of $4 \mathrm{~mm} /$ annum heralding imminent rupture, recurrence of symptoms or late development of malperfusion syndromes (42).

\section{Open surgery}

Open surgery for extensive thoracic and thoracoabdominal repair in cTBAD is associated with considerable risk of paraplegia or death, but this strategy may be considered if endovascular solutions are no option. A very important complication of open repair of spinal cord injury and despite the various new methods of prevention like cerebrospinal fluid drainage, active cooling, limitation of spinal cord collateral steal, maintenance of left subclavian artery patency, and close hemodynamic monitoring; those adjunct methods have improved outcomes, but the risk of paraplegia is still substantial (43). Open surgery for cTBAD involves replacement of the dissected aortic segment with excision of the septum and re-implantation of visceral, renal and, where appropriate, intercostal arteries (44). Typically, left heart bypass is used, but reasonable results have also been reported with the use of deep hypothermia to $18{ }^{\circ} \mathrm{C}$ at circulatory arrest (45-47). Contemporary experience suggests that open surgery can be performed at an acceptable risk in selected patients who are deemed fit for surgery and have connective tissue disorders $(44,48)$.

A "hybrid concept" combining open visceral re-routing (octopus-technique) and TEVAR of the remaining aorta may be a possible strategy in the chronic post-dissection state; however, lifetime surveillance is mandatory for detection of aneurysm enlargement, malperfusion or impending rupture even after TEVAR. Branched and fenestrated endovascular aortic repair is another option in patients with cTBAD, however, with no substantial 
Table 6 Recent studies of open surgery in chronic complicated type B dissection

\begin{tabular}{|c|c|c|c|c|c|c|}
\hline Study & $n$ & \multicolumn{3}{|c|}{ Early events (n) } & F/U duration (months) & Survival (\%) \\
\hline Miyamoto et al., 2008 (49) & & & & & 120 & 64 \\
\hline Goksel et al., 2008 (50) & 15 & 2 & NA & 0 & 36 & NA \\
\hline Takagi et al., 2010 (51) & & & & & 60 & 88 \\
\hline \multirow[t]{3}{*}{ Zoli et al., 2010 (52) } & 104 & 10 & 6 & 5 & 12 & 78 \\
\hline & & & & & 60 & 68 \\
\hline & & & & & 120 & 59 \\
\hline \multirow[t]{4}{*}{ Corvera et al., 2012 (45) } & 93 & 2 & 1 & 3 & 12 & 93 \\
\hline & & & & & 36 & 90 \\
\hline & & & & & 60 & 79 \\
\hline & & & & & 120 & 61 \\
\hline Nozdrzykowski et al., 2013 (54) & 15 & 2 & 2 & 2 & 36 & 75 \\
\hline \multirow[t]{3}{*}{ Conway et al., 2014 (55) } & 86 & 5 & 2 & 2 & 12 & 92 \\
\hline & & & & & 60 & 83 \\
\hline & & & & & 84 & 70 \\
\hline \multirow[t]{2}{*}{ Andersen et al., 2014 (58) } & 32 & 2 & 5 & 3 & 12 & 87 \\
\hline & & & & & 60 & 79 \\
\hline \multirow[t]{3}{*}{ Kouchoukos et al., 2015 (57) } & 69 & 4 & 2 & 4 & 12 & 87 \\
\hline & & & & & 60 & 65 \\
\hline & & & & & 120 & 40 \\
\hline Hata et al., 2015 (59) & 86 & 1 & 1 & NA & 36 & 96.4 \\
\hline Zhu et al., 2016 (60) & 45 & NA & NA & NA & 120 & 56.7 \\
\hline
\end{tabular}

CVA, cerebrovascular accident; SCI, spinal cord ischemia; F/U, follow-up; NA, not available.

data yet (45). In essence, open repair remains relevant for patients who are not candidates for endovascular repair, but is associated with higher procedural morbidity. The rates of stroke, paraplegia and operative mortality following endovascular repairs ranged from $5 \%$ to $13 \%, 2 \%$ to $13 \%$ and $2 \%$ to $13 \%$, respectively, while 5 -year survival rates ranged between $60 \%$ and $90 \%$ after open repair (44,45,49-60) (Table 6). 


\section{Endovascular repair}

In the absence of prospective, randomized trials there is consensus that TEVAR is the preferred treatment options with acute a subacute complicated dissection (61). This preference is less clear in the chronic phase as the true lumen is often small and the intimal flap is often rigid and non-compliable. Therefore, true lumen expansion and aortic remodelling is less likely than in the acute phase. Hence, the poor medical condition often seen in patients with chronic complicated TBAD may per se preclude extensive open surgical repair. Conversely, patients with extensive aneurysms often involving the entire thoracic or thoracoabdominal aorta and its branches have almost no option but conventional open surgery, although TEVAR in general is less traumatic and associated with lower morbidity and mortality (28). Frequent involvement of the abdominal aorta and their branches in type B dissection explains why TEVAR for chronic dissections is associated with high re-intervention rates (62). Another important issue is that the thickening of the dissection wall progresses with the chronicity of the TBAD, and may be less amenable to successful endo-grafting than in the acute phase. There is growing evidence that aortic remodelling is achieved more consistently when treated in the acute, rather than in the chronic phase of dissection. Recent data on endovascular repair of chronic complicated TBAD reveal excellent procedural and survival outcomes, but at the expense of further re-interventions. The rates of stroke following endovascular-based repair ranged between $0 \%$ to $5 \%$, it was $0 \%$ to $2 \%$ for paraplegia, up to $14 \%$ procedure-related mortality (20-25,58,60,63-74) (Table 7).

\section{Chronic uncomplicated TBAD}

\section{Medical management}

About 90\% type B dissection patients survive initial hospitalization and are subject to medical management with a 5 -year survival of 50-80\%, illustrating some efficacy of current medical therapy, but also the shortcoming considering the average mortality of $42 \%$ at 5 years (Table 8 ). According to IRAD observational findings, recurrent pain and uncontrolled hypertension are important prognostic factors and should be taken seriously as these clinical markers may herald impending rupture in the subacute and chronic stage.

The aim of medical therapy in the acute phase is to reduce shear stress impacting on the dissected segment of the aorta by reducing blood pressure and cardiac contractility as the driving forces. Thus, blood pressure control is the essential initial goal for patients with acute aortic dissection beside pain control.

As long as no complications are encountered with medical management in the initial phase with focus on strict blood pressure control this initial approach is accepted. Since open repair of the descending aorta has demonstrated prohibitively high morbidity of up to $31 \%$ is of course no potion at this stage. However, considering a morbidity of $30 \%$, including aneurysm degeneration of the affected segment, and an average mortality of $42 \%$ over 5 years endovascular strategies in addition to medical management has emerged as a valid option (77-80). Recent studies and registry data have identified high risk features in patients with uncomplicated type $\mathrm{B}$ dissection that may prompt pre-emptive thoracic endovascular aortic repair even early on.

\section{Open surgery}

Owing to advancements in endovascular techniques, open surgical repair for TBAD is only reserved for patients in whom even customized endovascular management is not feasible or has failed, with the aim to replace the dissected segment with a graft, restoring peripheral and visceral perfusion, and repairing or preventing aortic rupture. Currently, there are no level 1 data available to compare different surgical techniques and therefore the level of evidence regarding surgical treatment is low. Distal perfusion of the aorta with left-heart bypass or sequential aortic clamping combined with cerebrospinal fluid drainage, intrathecal papaverine, moderate hypothermia and reimplantation of intercostal arteries T7-L1 are adjuncts, with unproven benefit (81). Extracorporeal circulation and deep hypothermic arrest can be used when aortic crossclamping is no option. Accepted indications for open repair comprise complicated dissection considered not suitable for endovascular repair and patients with connective tissue disorders but fit for surgery. Such subpopulations have usually been the current stent-graft technology has been seen inappropriate for those fragile tissues. Interestingly, even in Marfan syndrome, however, TEVAR revealed acceptable morbidity and mortality, but also a high reintervention rate and disappointing impact on aortic remodelling (61).

\section{Endovascular repair}

There is on-going debate about the possible beneficial role of TEVAR in addition to medical management (Table 9). 
Table 7 Recent studies of endovascular repair in chronic complicated type B dissection.

\begin{tabular}{|c|c|c|c|c|c|c|}
\hline Study & $\mathrm{n}$ & \multicolumn{3}{|c|}{ Early events (n) } & F/U duration (months) & Survival (\%) \\
\hline Yang et al., 2006 (20) & 40 & 0 & 0 & 0 & 15 & NA \\
\hline Suzuki et al., 2006 (63) & 43 & 0 & 1 & 0 & 62 & NA \\
\hline Thompson et al., 2007 (64) & 52 & 1 & 2 & 0 & 5 & NA \\
\hline Jing et al., 2008 (21) & 35 & 0 & 0 & 0 & 48 & 92 \\
\hline Rodriguez et al., 2008 (23) & 47 & 7 & 2 & 1 & 15 & NA \\
\hline Sayer et al., 2008 (22) & 40 & 3 & 0 & 0 & 36 & 66 \\
\hline Alves et al., 2009 (25) & 61 & 2 & NA & NA & 36 & 93 \\
\hline \multirow[t]{2}{*}{ Chaikof et al., 2009 (66) } & 33 & NA & 1 & 0 & 12 & 73 \\
\hline & & & & & 60 & 41 \\
\hline Guangqi et al., 2009 (67) & 49 & 4 & 1 & 0 & 22 & NA \\
\hline Manning et al., 2009 (68) & 10 & 0 & 0 & NA & 56 & NA \\
\hline Czerny et al., 2010 (69) & 14 & 0 & 0 & 0 & 60 & 80 \\
\hline Parsa et al., 2011 (70) & 51 & 0 & 0 & 0 & 60 & 77 \\
\hline \multirow[t]{2}{*}{ Kang et al., 2011 (71) } & 76 & 4 & 1 & 0 & 12 & 86 \\
\hline & & & & & 24 & 82 \\
\hline \multirow[t]{3}{*}{ Lee et al., 2013 (74) } & 71 & 1 & NA & NA & 12 & 97.0 \\
\hline & & & & & 36 & 88.9 \\
\hline & & & & & 60 & 88.9 \\
\hline \multirow[t]{2}{*}{ Andersen et al., 2014 (58) } & 44 & 3 & 0 & 0 & 12 & 100 \\
\hline & & & & & 60 & 88 \\
\hline \multirow[t]{3}{*}{ Zhu et al., 2016 (60) } & 73 & NA & NA & NA & 12 & 97 \\
\hline & & & & & 60 & 82 \\
\hline & & & & & 120 & 26 \\
\hline
\end{tabular}

CVA, cerebrovascular accident; $\mathrm{SCl}$, spinal cord ischemia; F/U, follow-up; NA, not available. 
Table 8 Recent studies of medication only in chronic uncomplicated type B dissection

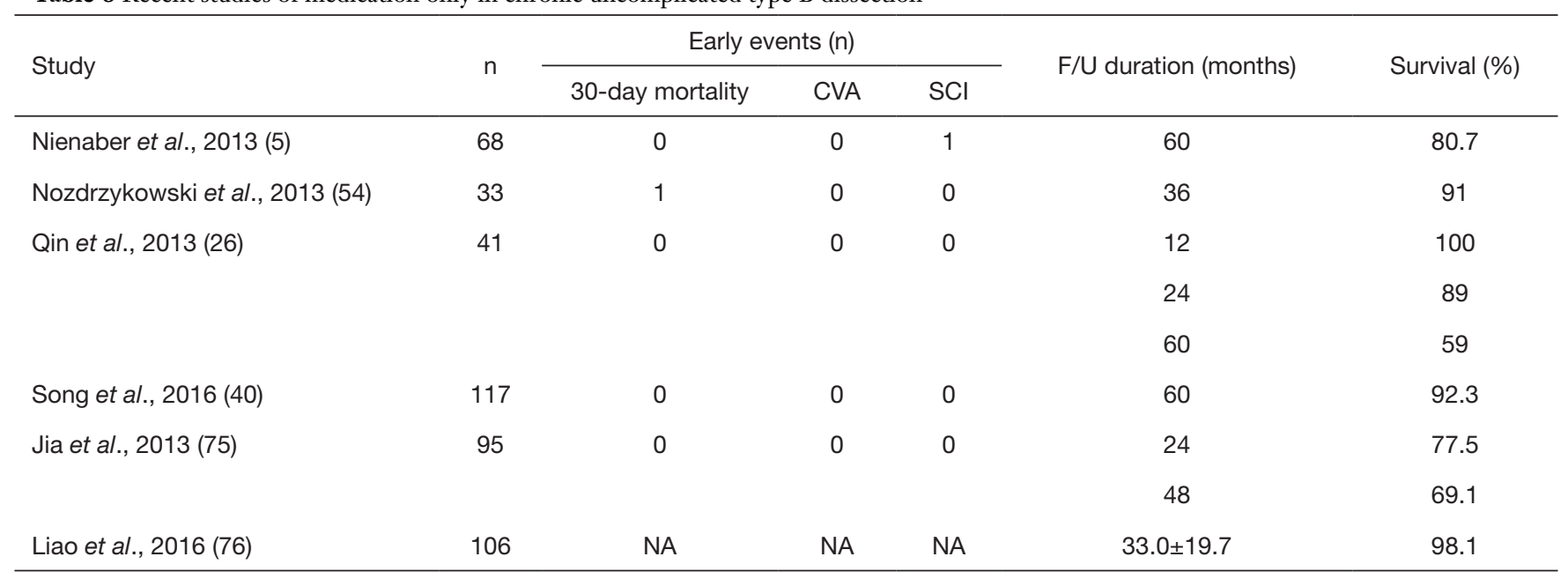

CVA, cerebrovascular accident; SCI, spinal cord ischemia; F/U, follow-up; NA, not available.

Table 9 Recent studies of endovascular repair in chronic uncomplicated type B dissection

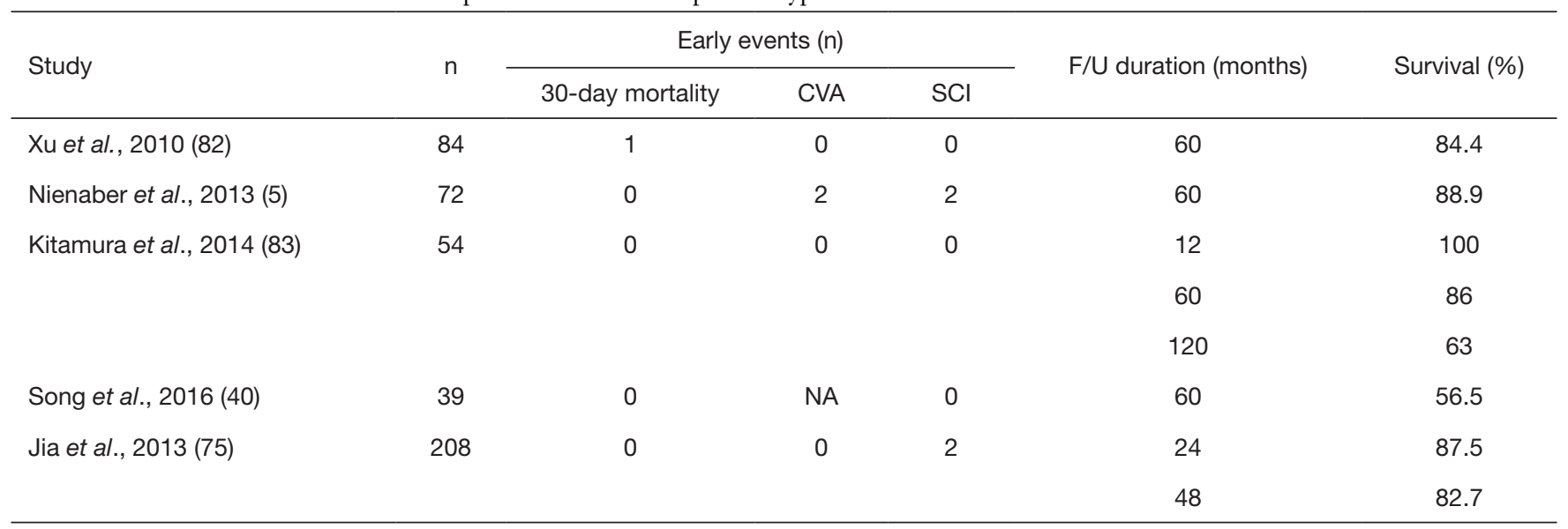

CVA, cerebrovascular accident; SCI, spinal cord ischemia; F/U, follow-up; NA, not available.

The first randomised trial of elective TEVAR in patients with subacute/chronic stable TBAD, the INvestigation of STEnt grafts in patients with type B Aortic Dissections (INSTEAD) trial, did not demonstrate a significant prognostic difference within 2 years, but showed better remodelling $(84,85)$. Long-term follow-up of those patients surviving over up to 5-7 years in INSTEDADXL showed that stent-graft induced active scaffolding can improve aortic-specific survival at 5 years; thus, preemptive TEVAR should be considered in clinically stable patients to improve late outcomes by induced remodelling. This trial also showed that endovascular repair is still associated with vascular complications, such as stroke and paraplegia in $8.6 \%$, and that aortic events continue to occur even after endovascular treatment (5). For patients with uncomplicated TBAD, effective blood pressure lowering medication is widely accepted as the standard initial management, together with consideration for endovascular repair. However, up 20-55\% of medically treated patients may develop aneurysmal degeneration after 5 years $(5,33,39,40,86-89)$ attributed to incomplete aortic remodelling. The concept of post-dissection aortic remodelling is important since a large entry tear, the location of it, true versus false lumen ratio and the amount of false lumen flow have a negative impact on prognosis (89-90). Both, absent or incomplete false lumen thrombosis are considered predictors of mortality and aortic growth and should be targeted $(91,92)$. 


\section{Discussion}

Optimal management of patients with TBAD is challenging and requires a multidisciplinary team approach. The term "uncomplicated" type B dissection is tricky and could in fact be a misnomer as many "uncomplicated" asymptomatic cases reveal high risk features of dissection even without overt complications. Conversely, prevention of chronic aneurysmal degeneration and attainment of aortic remodelling with pre-emptive TEVAR may avoid late degeneration and hence complex open aortic surgery with its inherent risks. INSTEAD-XL and ADSORB have sent the signal that pre-emptive TEVAR for uncomplicated TBAD may indeed improve long-term prognosis. Therefore, repeat imaging between 14 days and 3 months may detect high risk features and impending complications within the time window of plasticity allowing successful remodelling by TEVAR. The indication for a preventive procedure is reportedly any progression to a maximum aortic diameter $>44 \mathrm{~mm}$ during the subacute phase and a patent primary entry site in the thoracic aorta, while the optimal timing for TEVAR would be in the phase before closure of the window plasticity at 3 months, in the attempt to convert absent or partial false lumen thrombosis into complete thrombosis and avoid further aortic.

While the term "complicated" is actually well defined and understood, the term "uncomplicated" type B dissection seems to be less clearly defined. For complicated cases, treated acutely, the 30-day or in-hospital mortality was $7.3 \%$ in patients managed by endovascular, whereas the pooled rate for 30-day or in-hospital mortality was $19.0 \%$ when subjected to open repair. Cerebrovascular events and SCI occurred more frequently in the operative group. Interestingly, the survival rates at 1 and 5 years were comparable between patients subjected to surgical or non-surgical management although no randomized trials exist (Tables 3,5). The consensus seems to be to avoid open surgery and offer surveillance to all the patients after endovascular repair. Indeed, all patients, regardless of initial presentation and choice of treatment need to be under medical management and surveillance. Standard medical treatment comprises $\beta$-blockers and if necessary diuretics, angiotensin-converting enzyme inhibitors, calcium blockers and/or $\alpha$-blockers. The primary goal is to target a systolic blood pressure between 100 to $120 \mathrm{mmHg}$ and thus reduce the shear stress of the aortic wall while maintaining urinary output and visceral perfusion (34). However, blood pressure control alone does not necessarily prevent any disease progression to complicated dissection or aneurysmal degeneration $(3,4,85)$. Thus, surveillance is advocated and imaging should be offered even to asymptomatic patients.

When so-called uncomplicated acute type B dissection was treated with blood pressure lowering medications, the pooled 30-day or in-hospital mortality rate was $2.4 \%$; survival rates at 5 years, however, were reported between $59.0 \%$ to $97.2 \%$, at an average of $60.0 \%$. Freedom from any aortic event ranged from $34.0 \%$ to $83.9 \%$, underlining an inherent risk of progression and late complications. Favourable long-term stability induced by pre-emptive stenting and high rate of aortic remodelling was confirmed by the results of the INSTEAD-XL randomized trial in addition to medical therapy (5).

High risk features for subacute and/or late complications in the setting of "uncomplicated" distal aortic dissection seem to be pivotal in picking the right management strategy. Various studies have suggested several prognostic factors of early or late adverse events such as patency of the false lumen during follow-up, an initial aortic diameter $\geq 42 \mathrm{~mm}$ with a patent false lumen, an initial false lumen diameter $\geq 22 \mathrm{~mm}$ in thoracic descending segments, visceral involvement and recurrent or refractory pain or hypertension (93-97). Partial thrombosis of the false lumen, a proximal entry tear size $>10 \mathrm{~mm}$ and spiral configuration (of the dissection) have also been suggested to be associated with an increasing risk of aortic growth. The new "high risk" features need to be taken in consideration when selecting the appropriate treatment strategy for a given patient deemed "uncomplicated" after type B dissection (Figure 1).

Our study has inherent limitations associated with any such meta-analysis. A considerable heterogeneity seen amongst selected reports may reflect varying patient characteristics between studies. Hence, these pooled estimates without raw individual patient data prohibit any deep subset analysis; therefore, results should be interpreted with caution and recommendations may contain some personal flavour.

\section{Conclusions}

Currently, the less invasive strategy of an endovascular repair (as compared to open surgery) provides improved 30-day or in-hospital survival in the setting of complicated aTBAD. Open surgical aortic reconstruction should be left to experienced aortic centres if endovascular management is not an option. Although the ideal treatment for 

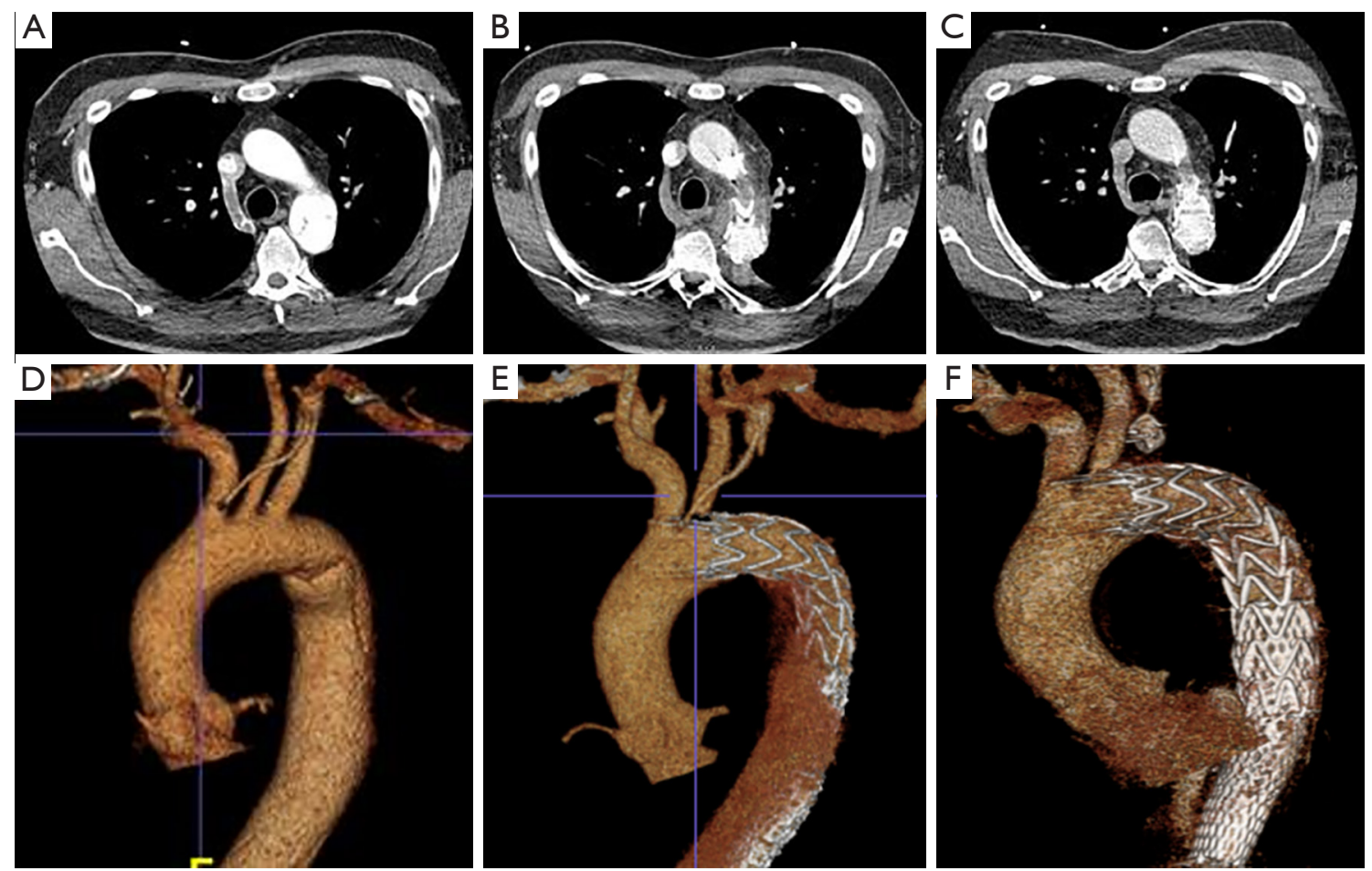

Figure 1 Case of a 55-year-old male patient with the clinical diagnosis of "uncomplicated" type B aortic dissection diagnosed and followed by 2D- and 3D-CT angiography. (A) and (D) show diagnostic CT images revealing a classic type B aortic dissection with a large (>10 mm) entry tear and a fully perfused false lumen. As shown on (B) and (E), the patient was selected for elective TEVAR (including a carotidsubclavian bypass and an occluder placed in the left subclavian artery) at 4 weeks after impact of dissection. Finally, (C) and (F) show the results after 3 months of follow-up with complete remodelling and disappearance of the false lumen; medical management will be continued for life. TEVAR, thoracic endovascular aortic repair.

"uncomplicated" aTBAD is still not unequivocally and fully clarified, the combination of TEVAR with antihypertensive therapy seems to reveal a more favourable long-term outcome as a result of successful aortic remodelling when compared with medical management alone. The term "uncomplicated" type B dissection is gradually undergoing important changes as many high-risk features (of socalled uncomplicated dissection) are better understood and thus may qualify a given patient to sooner pre-emptive endovascular repair. Finally, the vascular community feels some need for prospective clinical registries that will focus on both prognostic factors for early and late complications in any TBAD, and on various choices of pro-active management.

\section{Acknowledgements}

None.

\section{Footnote}

Conflicts of Interest: The authors have no conflicts of interest to declare.

\section{References}

1. Coady MA, Ikonomidis JS, Cheung AT, et al. Surgical management of descending thoracic aortic disease: open and endovascular approaches: a scientific statement from the American Heart Association. Circulation 2010;121:2780-804.

2. Fattori R, Cao P, De Rango P, et al. Interdisciplinary expert consensus document on management of type $\mathrm{B}$ aortic dissection. J Am Coll Cardiol 2013;61:1661-78.

3. Tsai TT, Trimarchi S, Nienaber CA. Acute aortic dissection: perspectives from the International Registry of Acute Aortic Dissection (IRAD). Eur J Vasc Endovasc Surg 2009;37:149-59. 
4. Tsai TT, Evangelista A, Nienaber CA, et al. Longterm survival in patients presenting with type A acute aortic dissection: insights from the International Registry of Acute Aortic Dissection (IRAD). Circulation 2006;114:1350-6.

5. Nienaber CA, Kische S, Rousseau H, et al. Endovascular repair of type $\mathrm{B}$ aortic dissection: long-term results of the randomized investigation of stent grafts in aortic dissection trial. Circ Cardiovasc Interv 2013;6:407-16.

6. Qin YL, Wang F, Li TX, et al. Endovascular Repair Compared With Medical Management of Patients With Uncomplicated Type B Acute Aortic Dissection. J Am Coll Cardiol 2016;67:2835-42.

7. Chemelli-Steingruber I, Chemelli A, Strasak A, et al. Endovascular repair or medical treatment of acute type B aortic dissection? A comparison. Eur J Radiol 2010;73:175-80.

8. Tolenaar JL, Froehlich W, Jonker FH, et al. Predicting in-hospital mortality in acute type B aortic dissection: evidence from International Registry of Acute Aortic Dissection. Circulation 2014;130:S45-50.

9. Estrera AL, Miller CC 3rd, Safi HJ, et al. Outcomes of medical management of acute type B aortic dissection. Circulation 2006;114:I384-9.

10. Trimarchi S, Nienaber CA, Rampoldi V, et al. Role and results of surgery in acute type B aortic dissection: insights from the International Registry of Acute Aortic Dissection (IRAD). Circulation 2006;114:I357-64.

11. Bozinovski J, Coselli JS. Outcomes and survival in surgical treatment of descending thoracic aorta with acute dissection. Ann Thorac Surg 2008;85:965-70; discussion 970-1.

12. Shimokawa T, Horiuchi K, Ozawa N, et al. Outcome of surgical treatment in patients with acute type B aortic dissection. Ann Thorac Surg 2008;86:103-7.

13. Zeeshan A, Woo EY, Bavaria JE, et al. Thoracic endovascular aortic repair for acute complicated type B aortic dissection: superiority relative to conventional open surgical and medical therapy. J Thorac Cardiovasc Surg 2010;140:S109-15; discussion S142-6.

14. Brunt ME, Egorova NN, Moskowitz AJ. Propensity score-matched analysis of open surgical and endovascular repair for type B aortic dissection. Int J Vasc Med 2011;2011:364046.

15. Murashita T, Ogino H, Matsuda H, et al. Clinical outcome of emergency surgery for complicated acute type B aortic dissection. Circ J 2012;76:650-4.

16. Minami T, Imoto K, Uchida K, et al. Mid-term outcomes of acute type B aortic dissection in Japan single center. Ann Thorac Cardiovasc Surg 2013;19:461-7.

17. Wilkinson DA, Patel HJ, Williams DM, et al. Early open and endovascular thoracic aortic repair for complicated type B aortic dissection. Ann Thorac Surg 2013;96:23-30; discussion 230.

18. Di Tommaso L, Monaco M, Mottola M, et al. Major complications following endovascular surgery of descending thoracic aorta. Interact Cardiovasc Thorac Surg 2006;5:705-8.

19. Chen S, Yei F, Zhou L, et al. Endovascular stent-grafts treatment in acute aortic dissection (type B): clinical outcomes during early, late, or chronic phases. Catheter Cardiovasc Interv 2006;68:319-25.

20. Yang J, Zuo J, Yang L, et al. Endovascular stent-graft treatment of thoracic aortic dissection. Interact Cardiovasc Thorac Surg 2006;5:688-91.

21. Jing QM, Han YL, Wang XZ, et al. Endovascular stentgrafts for acute and chronic type B aortic dissection: comparison of clinical outcomes. Chin Med J (Engl) 2008;121:2213-7.

22. Sayer D, Bratby M, Brooks M, et al. Aortic morphology following endovascular repair of acute and chronic type B aortic dissection: implications for management. Eur J Vasc Endovasc Surg 2008;36:522-9.

23. Rodriguez JA, Olsen DM, Lucas L, et al. Aortic remodeling after endografting of thoracoabdominal aortic dissection. J Vasc Surg 2008;47:1188-94.

24. Böckler D, Hyhlik-Durr A, Hakimi M, et al. Type B aortic dissections: treating the many to benefit the few? J Endovasc Ther 2009;16 Suppl 1:I80-90.

25. Alves CM, da Fonseca JH, de Souza JA, et al. Endovascular treatment of type B aortic dissection: the challenge of late success. Ann Thorac Surg 2009;87:1360-5.

26. Qin YL, Deng G, Li TX, et al. Treatment of acute type-B aortic dissection: thoracic endovascular aortic repair or medical management alone? JACC Cardiovasc Interv 2013;6:185-91.

27. Shu C, Fang K, Luo M, et al. Emergency endovascular stent-grafting for acute type $\mathrm{B}$ aortic dissection with symptomatic malperfusion. Int Angiol 2013;32:483-91.

28. Eggebrecht H, Nienaber CA, Neuhauser $M$, et al. Endovascular stent-graft placement in aortic dissection: a meta-analysis. Eur Heart J 2006;27:489-98.

29. Grabenwöger M, Alfonso F, Bachet J, et al. Thoracic Endovascular Aortic Repair (TEVAR) for the treatment of aortic diseases: a position statement from the European Association for Cardio-Thoracic Surgery 
(EACTS) and the European Society of Cardiology (ESC), in collaboration with the European Association of Percutaneous Cardiovascular Interventions (EAPCI). Eur J Cardiothorac Surg 2012;42:17-24.

30. Jakob H, Dohle DS, Piotrowski J, et al. Six-year experience with a hybrid stent graft prosthesis for extensive thoracic aortic disease: an interim balance. Eur J Cardiothorac Surg 2012;42:1018-25.

31. Cao P, De Rango P, Czerny M, e al. Systematic review of clinical outcomes in hybrid procedures for aortic arch dissections and other arch diseases. J Thorac Cardiovasc Surg 2012;144:1286-300, 1300.e1-2.

32. Nienaber CA, Kische S, Zeller T, et al. Provisional extension to induce complete attachment after stent-graft placement in type B aortic dissection: the PETTICOAT concept. J Endovasc Ther 2006;13:738-46.

33. Brunkwall J, Kasprzak P, Verhoeven E, et al. Endovascular repair of acute uncomplicated aortic type B dissection promotes aortic remodelling: 1 year results of the ADSORB trial. Eur J Vasc Endovasc Surg 2014;48:285-91. Erratum in: Eur J Vasc Endovasc Surg 2015;50:130.

34. Estrera AL, Miller CC, Goodrick J, et al. Update on outcomes of acute type B aortic dissection. Ann Thorac Surg 2007;83:S842-5; discussion S846-50.

35. Kitada S, Akutsu K, Tamori Y, et al. Usefulness of fibrinogen/fibrin degradation product to predict poor oneyear outcome of medically treated patients with acute type B aortic dissection. Am J Cardiol 2008;101:1341-4.

36. Niino T, Hata M, Sezai A, et al. Optimal clinical pathway for the patient with type B acute aortic dissection. Circ J 2009;73:264-8.

37. Dick F, Hirzel C, Immer FF, et al. Quality of life after acute type $\mathrm{B}$ dissection in the era of thoracic endovascular aortic repair. Vasa 2010;39:219-28.

38. Miyahara S, Mukohara N, Fukuzumi M, et al. Longterm follow-up of acute type B aortic dissection: ulcer-like projections in thrombosed false lumen play a role in late aortic events. J Thorac Cardiovasc Surg 2011;142:e25-31.

39. Afifi RO, Sandhu HK, Leake SS, et al. Outcomes of Patients With Acute Type B (DeBakey III) Aortic Dissection: A 13-Year, Single-Center Experience. Circulation 2015;132:748-54.

40. Song C, Lu Q, Zhou J, et al. The new indication of TEVAR for uncomplicated type B aortic dissection. Medicine (Baltimore) 2016;95:e3919.

41. Hiratzka LF, Bakris GL, Beckman JA, et al. 2010 ACCF/AHA/AATS/ACR/ASA/SCA/SCAI/SIR/STS/ SVM Guidelines for the diagnosis and management of patients with thoracic aortic disease. A Report of the American College of Cardiology Foundation/American Heart Association Task Force on Practice Guidelines, American Association for Thoracic Surgery, American College of Radiology,American Stroke Association, Society of Cardiovascular Anesthesiologists, Society for Cardiovascular Angiography and Interventions, Society of Interventional Radiology, Society of Thoracic Surgeons, and Society for Vascular Medicine. J Am Coll Cardiol 2010;5 5:e27-129.

42. Svensson LG, Kouchoukos NT, Miller DC, et al. Expert consensus document on the treatment of descending thoracic aortic disease using endovascular stent-grafts. Ann Thorac Surg 2008;85:S1-41.

43. Tian DH, De Silva RP, Wang T, et al. Open surgical repair for chronic type B aortic dissection: a systematic review. Ann Cardiothorac Surg 2014;3:340-50.

44. Pujara AC, Roselli EE, Hernandez AV, et al. Open repair of chronic distal aortic dissection in the endovascular era: Implications for disease management. J Thorac Cardiovasc Surg 2012;144:866-73.

45. Corvera JS, Fehrenbacher JW. Open repair of chronic aortic dissections using deep hypothermia and circulatory arrest. Ann Thorac Surg 2012;94:78-81; discussion 82-3.

46. Geisbüsch P, Kotelis D, von Tengg-Kobligk H, et al. Thoracic aortic endografting in patients with connective tissue diseases. J Endovasc Ther 2008;15:144-9.

47. Mommertz G, Sigala F, Langer S, et al. Thoracoabdominal aortic aneurysm repair in patients with marfan syndrome. Eur J Vasc Endovasc Surg 2008;35:181-6.

48. Estrera AL, Sandhu HK, Afifi RO, et al. Early and Late Outcomes After Complete Aortic Replacement. Ann Thorac Surg 2015;100:528-34.

49. Miyamoto Y, Ohata T, Mitsuno M, et al. Long-term outcomes after entry closure and aneurysmal wall plication for type B aortic dissection. Eur J Cardiothorac Surg 2008;33:152-6.

50. Goksel OS, Tireli E, Kalko Y, et al. Mid-term outcome with surgery for type $\mathrm{B}$ aortic dissections: a single center experience. J Card Surg 2008;23:27-30.

51. Takagi Y, Ando M, Higuchi Y, et al. Recent outcomes of surgery for chronic type B aortic dissection. Ann Vasc Dis 2010;3:215-21.

52. Zoli S, Etz CD, Roder F, et al. Long-term survival after open repair of chronic distal aortic dissection. Ann Thorac Surg 2010;89:1458-66.

53. Mutsuga M, Narita Y, Araki Y, et al. Spinal cord protection during a thoracoabdominal aortic repair for a chronic 
type B aortic dissection using the aortic tailoring strategy. Interact Cardiovasc Thorac Surg 2010;11:15-9.

54. Nozdrzykowski M, Etz CD, Luehr M, et al. Optimal treatment for patients with chronic Stanford type B aortic dissection: endovascularly, surgically or both? Eur J Cardiothorac Surg 2013;44:e165-74; discussion e174.

55. Conway AM, Sadek M, Lugo J, et al. Outcomes of open surgical repair for chronic type B aortic dissections. J Vasc Surg 2014;59:1217-23.

56. Estrera AL, Sandhu H, Afifi RO, et al. Open repair of chronic complicated type $\mathrm{B}$ aortic dissection using the open distal technique. Ann Cardiothorac Surg 2014;3:375-84.

57. Kouchoukos NT, Kulik A, Castner CF. Open thoracoabdominal aortic repair for chronic type B dissection. J Thorac Cardiovasc Surg 2015;149:S125-9.

58. Andersen ND, Keenan JE, Ganapathi AM, et al. Current management and outcome of chronic type B aortic dissection: results with open and endovascular repair since the advent of thoracic endografting. Ann Cardiothorac Surg 2014;3:264-74.

59. Hata M, Orime Y, Wakui S, et al. Outcomes of Open Surgical Repair for Type B Dissecting Aortic Aneurysm With Alternative Methods in the Endovascular Stent Era. Seminars in Thoracic and Cardiovascular Surgery 2015;27:106-12.

60. Zhu Y, Wang B, Meng Q, et al. Long-term efficacy of endovascular vs open surgical repair for complicated type-B aortic dissection: a single-center retrospective study and meta-analysis. Braz J Med Biol Res 2016;49:e5194.

61. Erbel R, Aboyans V, Boileau C, et al. 2014 ESC Guidelines on the diagnosis and treatment of aortic diseases:

Document covering acute and chronic aortic diseases of the thoracic and abdominal aorta of the adult. The Task Force for the Diagnosis and Treatment of Aortic Diseases of the European Society of Cardiology (ESC). Eur Heart J 2014;35:2873-926.

62. Kamman AV, de Beaufort HWL, van Bogerijen GHW, et al. Contemporary Management Strategies for Chronic Type B Aortic Dissections: A Systematic Review. PLoS One 2016;11:e0154930.

63. Suzuki S, Imoto K, Uchida K, et al. Midterm results of transluminal endovascular grafting in patients with DeBakey type III dissecting aortic aneurysms. Ann Thorac Cardiovasc Surg 2006;12:42-9.

64. Thompson M, Ivaz S, Cheshire N, et al. Early results of endovascular treatment of the thoracic aorta using the Valiant endograft. Cardiovasc Intervent Radiol
2007;30:1130-8.

65. Flecher E, Cluzel P, Bonnet N, et al. Endovascular treatment of descending aortic dissection (type B): short- and medium-term results. Arch Cardiovasc Dis 2008;101:94-9.

66. Chaikof EL, Mutrie C, Kasirajan K, et al. Endovascular repair for diverse pathologies of the thoracic aorta: an initial decade of experience. J Am Coll Surg 2009;208:80216; discussion 816-8.

67. Guangqi C, Xiaoxi L, Wei C, et al. Endovascular repair of Stanford type B aortic dissection: early and midterm outcomes of 121 cases. Eur J Vasc Endovasc Surg 2009;38:422-6.

68. Manning BJ, Dias N, Ohrlander T, et al. Endovascular treatment for chronic type B dissection: limitations of short stent-grafts revealed at midterm follow-up. J Endovasc Ther 2009;16:590-7.

69. Czerny M, Roedler S, Fakhimi S, et al. Midterm results of thoracic endovascular aortic repair in patients with aneurysms involving the descending aorta originating from chronic type B dissections. Ann Thorac Surg 2010;90:90-4.

70. Parsa CJ, Williams JB, Bhattacharya SD, et al. Midterm results with thoracic endovascular aortic repair for chronic type B aortic dissection with associated aneurysm. J Thorac Cardiovasc Surg 2011;141:322-7.

71. Kang WC, Greenberg RK, Mastracci TM, et al. Endovascular repair of complicated chronic distal aortic dissections: intermediate outcomes and complications. J Thorac Cardiovasc Surg 2011;142:1074-83.

72. Mani K, Clough RE, Lyons OT, et al. Predictors of outcome after endovascular repair for chronic type B dissection. Eur J Vasc Endovasc Surg 2012;43:386-91.

73. Andacheh ID, Donayre C, Othman F, et al. Patient outcomes and thoracic aortic volume and morphologic changes following thoracic endovascular aortic repair in patients with complicated chronic type B aortic dissection. J Vasc Surg 2012;56:644-50; discussion 650.

74. Lee M, Lee DY, Kim MD, et al. Outcomes of endovascular management for complicated chronic type B aortic dissection: effect of the extent of stent graft coverage and anatomic properties of aortic dissection. J Vasc Interv Radiol 2013;24:1451-60.

75. Jia X, Guo W, Li TX, et al. The results of stent graft versus medication therapy for chronic type B dissection. J Vasc Surg 2013;57:406-14.

76. Liao KM, Chen CY, Wang SH, et al. A Retrospective Observational Study to Assess Prescription Pattern in 
Patients with Type B Aortic Dissection and Treatment Outcome. Biomed Res Int 2016;2016:5173898.

77. Kato N, Shimono T, Hirano T, et al. Midterm results of stent-graft repair of acute and chronic aortic dissection with descending tear: the complication-specific approach. J Thorac Cardiovasc Surg 2002;124:306-12.

78. Bogdan Y, Hines GL. Management of acute complicated and uncomplicated type B dissection of the aorta: focus on endovascular stent grafting. Cardiol Rev 2010;18:234-9.

79. Umaña JP, Lai DT, Mitchell RS, et al. Is medical therapy still the optimal treatment strategy for patients with acute type B aortic dissections? J Thorac Cardiovasc Surg 2002;124:896-910.

80. Acosta S, Blomstrand D, Gottsater A. Epidemiology and long-term prognostic factors in acute type B aortic dissection. Ann Vasc Surg 2007;21:415-22.

81. Schepens MA. Left heart bypass for thoracoabdominal aortic aneurysm repair: technical aspects. Multimed Man Cardiothorac Surg 2016;2016. doi: 10.1093/mmcts/mmv039.

82. Xu SD, Huang FJ, Yang JF, et al. Early and midterm results of thoracic endovascular aortic repair of chronic type B aortic dissection. J Thorac Cardiovasc Surg 2010;139:1548-53.

83. Kitamura T, Torii S, Oka N, et al. Key success factors for thoracic endovascular aortic repair for non-acute Stanford type B aortic dissection. Eur J Cardiothorac Surg 2014;46:432-7; discussion 437.

84. Nienaber CA, Zannetti S, Barbieri B, et al. INvestigation of STEnt grafts in patients with type B Aortic Dissection: design of the INSTEAD trial--a prospective, multicenter, European randomized trial. Am Heart J 2005;149:592-9.

85. Nienaber CA, Rousseau H, Eggebrecht H, et al. Randomized comparison of strategies for type B aortic dissection: the INvestigation of STEnt Grafts in Aortic Dissection (INSTEAD) trial. Circulation 2009; 120:2519-28.

86. Booher AM, Isselbacher EM, Nienaber CA, et al. The IRAD classification system for characterizing survival after aortic dissection. Am J Med 2013;126:730.e19-24.

87. Luebke T, Brunkwall J. Type B Aortic Dissection: A Review of Prognostic Factors and Meta-analysis of

doi: 10.21037/jovs.2018.02.15

Cite this article as: Yuan X, Mitsis A, Ghonem M, Iakovakis I, Nienaber CA. Conservative management versus endovascular or open surgery in the spectrum of type B aortic dissection. J Vis Surg 2018;4:59.
Treatment Options. Aorta (Stamford) 2014;2:265-78.

88. Fattori R, Montgomery D, Lovato L, et al. Survival after endovascular therapy in patients with type B aortic dissection: a report from the International Registry of Acute Aortic Dissection (IRAD). JACC Cardiovasc Interv 2013;6:876-82.

89. van Bogerijen GH, Tolenaar JL, Rampoldi V, et al. Predictors of aortic growth in uncomplicated type B aortic dissection. J Vasc Surg 2014;59:1134-43.

90. Erbel R, Oelert H, Meyer J, et al. Effect of medical and surgical therapy on aortic dissection evaluated by transesophageal echocardiography. Implications for prognosis and therapy. The European Cooperative Study Group on Echocardiography. Circulation 1993;87:1604-15.

91. Tsai TT, Evangelista A, Nienaber CA, et al. Partial thrombosis of the false lumen in patients with acute type $B$ aortic dissection. N Engl J Med 2007;357:349-59.

92. Sueyoshi E, Nagayama H, Hayashida T, et al. Fate of aorta and clinical outcomes in patients with chronic type B aortic dissection: over 20-year experience. J Cardiovasc Surg (Torino) 2014;5 5:247-55.

93. Winnerkvist A, Lockowandt U, Rasmussen E, et al. A prospective study of medically treated acute type B aortic dissection. Eur J Vasc Endovasc Surg 2006;32:349-55.

94. Kitai T, Kaji S, Yamamuro A, et al. Impact of new development of ulcer-like projection on clinical outcomes in patients with type $\mathrm{B}$ aortic dissection with closed and thrombosed false lumen. Circulation 2010;122:S74-80.

95. Marui A, Mochizuki T, Koyama T, et al. Degree of fusiform dilatation of the proximal descending aorta in type B acute aortic dissection can predict late aortic events. J Thorac Cardiovasc Surg 2007;134:1163-70.

96. Song JM, Kim SD, Kim JH, et al. Long-term predictors of descending aorta aneurysmal change in patients with aortic dissection. J Am Coll Cardiol 2007;50:799-804.

97. Trimarchi S, Eagle KA, Nienaber CA, et al. Importance of refractory pain and hypertension in acute type B aortic dissection: insights from the International Registry of Acute Aortic Dissection (IRAD). Circulation 2010;122:1283-9. 